\title{
CONTRABANDO TÉCNICO Y POLÍTICA ARANCELARIA: ANÁLISIS DE DATOS DE PANEL PARA EL SECTOR TEXTIL COLOMBIANO
}

\author{
Recibido: 05 de febrero de 2018 - Aprobado: 08 de agosto de 2018 \\ https://doi.org/10.22395/seec.v21n48a6 \\ Carolina Vélez Ospina** \\ Edwin Esteban Torres Gómez ***
}

\section{RESUMEN}

En el periodo comprendido entre 1990 hasta la segunda década del 2000, el sector textil colombiano se ha enfrentado a frecuentes modificaciones de política arancelaria, estas reformas han tenido el propósito de mejorar las condiciones económicas del sector por medio de dos estrategias: proteger al sector ante la creciente competencia internacional y reducir el problema del contrabando por subfacturación de importaciones. Es por esto que este artículo evalúa el efecto de estas políticas en el contrabando y en la situación del mercado laboral, haciendo uso de modelación econométrica para datos de panel. Los resultados sugieren que las políticas tuvieron efectos adversos sobre la subfacturación y sobre las horas trabajadas de los empleados, afectando mayoritariamente al empleo informal.

\section{PALABRAS CLAVE}

Subfacturación; contrabando; aranceles; sector textil; panel de datos.

\section{CLASIFICACIÓN JEL}

E26, F13, F14, F19, C23.

\section{CONTENIDO}

Introducción; 1. Política arancelaria en Colombia; 2. Revisión de literatura; 3. Metodología y datos;

4. Resultados; 5. Conclusiones; Bibliografía.

* Este artículo de investigación está basado en el trabajo de grado de Carolina Vélez para optar al título de Economista de la Facultad de Ciencias Económicas de la Universidad de Antioquia, asesorada por Edwin Torres y hace parte del grupo de investigación de Macroeconomía Aplicada (clasificado en B por Colciencias en 2017). El trabajo se desarrolló en el periodo de agosto-diciembre del 2017.

* Economista Universidad de Antioquia, Medellín, Colombia. Joven Investigadora, Universidad del Rosario, Facultad de Economía, Bogotá, Colombia. Tel: 571 2970200, Ext. 4912. Correo electrónico: carolinavelezospina@gmail.com.

*.* Economista Universidad de Antioquia, Medellín, Colombia. Magíster en Economía, Universidad del Rosario, Bogotá, Colombia. Candidato a Doctor en Economía, Universidad del Rosario, Bogotá, Colombia. Profesor e investigador, Universidad de Antioquia, Grupo de Macroeconomía Aplicada. Medellín, Colombia, Tel: 574 2198823.Correo electrónico: esteban.torres@udea.edu.co. 


\title{
TECHNICAL CONTRABAND AND TARIFF POLICY: PANEL DATA ANALYSIS OF THE COLOMBIAN TEXTILE SECTOR
}

\begin{abstract}
Between 1990 and the second decade of 2000, the Colombian textile sector has faced frequent changes in tariff policies. These reforms aimed at improving the sector's economic conditions through two strategies: protecting the sector against the growing international competition and reducing the problem of smuggling due to underinvoicing of imports. This article evaluates the effect of such policies on contraband and the labor market situation, making use of panel data econometric modeling. The results suggest that the policies had adverse effects on under-invoicing and on the hours worked by employees, mostly affecting informal employment.
\end{abstract}

\section{KEYWORDS}

Under-invoicing; smuggling; tariff; textile sector; data panel.

\section{JEL CLASSIFICATION}

E26, F13, F14, F19, C23.

\section{CONTENT}

Introduction; 1. Colombia's tariff policy; 2. Literature review; 3. Methodology and data; 4. Results;

5. Conclusions; Bibliography.

\section{CONTRABANDO TÉCNICO E POLIITICA TARIFÁRIA: ANÁLISE DE DADOS DE PAINEL PARA O SETOR TÊXTIL COLOMBIANO}

\section{RESUMO}

No período compreendido entre 1990 até a segunda década de 2000, o setor têxtil colombiano enfrentou frequentes modificações de política tarifária. Essas reformas tiveram o propósito de melhorar as condições econômicas do setor por meio de duas estratégias: proteger o setor ante a crescente concorrência internacional e reduzir o problema do contrabando por subfaturamento de importações. Nesse sentido, este artigo avalia o efeito dessas políticas no contrabando e na situação do mercado profissional, fazendo uso de modelação econométrica para dados de painel. Os resultados sugerem que as políticas tenham tido efeitos adversos sobre o subfaturamento e sobre as horas trabalhadas dos empregados, o que afetou em grande medida o emprego informal.

\section{PALAVRAS-CHAVE}

Subfaturamento; contrabando; tarifas; setor têxtil; painel de dados.

\section{CLASSIFICAÇÃO JEL}

E26, F13, F14, F19, C23.

\section{CONTEÚDO}

Introdução; 1. Política tarifária na Colômbia; 2. Revisão de literatura; 3. Metodologia e dados; 4. Resultados; 5. Conclusões; Bibliografia. 


\section{INTRODUCCIÓN}

El sector textil en Colombia se destaca por tener una participación importante sobre la producción agregada de la industria manufacturera, esto se ha podido corroborar a lo largo del periodo 2000-2016 cuando ha alcanzado una participación promedio de $11,9 \%$, y ha obtenido su mayor contribución en los años 2007-2008 y su menor desempeño en 2010, luego de la crisis mundial, con un 11,2\%. Además, este sector se caracteriza por contribuir activamente en la creación de empleo y en la generación de encadenamientos hacia atrás y hacia adelante, lo que permite catalogarlo como un renglón económico estratégico en la economía colombiana. Sin embargo, en términos de inversión e innovación, el sector se ha quedado corto, pues en la última década se han disminuido considerablemente las inversiones realizadas en maquinaria, llegando a niveles menores al $10 \%{ }^{2}$, lo que termina generando productos más costosos y de menor calidad, es decir, productos menos competitivos. Esto puede explicarse por medio de algunas hipótesis de desindustrialización económica que destacan algunos autores para este periodo en Colombia (Torres y López, 2016).

Esta problemática se ve reflejada en la aparición de un cambio importante en el comportamiento del sector en el mercado internacional, ya que en los últimos años, la participación de las importaciones sobre el volumen del comercio ${ }^{3}$ ha aumentado considerablemente, pasando del $21 \%$ en 2005, hasta alcanzar cifras del $65 \%$ en 2016. Esto ha tenido como repercusión una balanza comercial deficitaria, hecho que no se evidenciaba para los años anteriores a 2009 y que muestra la pérdida de capacidad del sector textil para incursionar en los mercados internacionales y para asumir la demanda local.

En vista de este resultado, y dada la importancia del sector, ha crecido la preocupación del gobierno por promover la estabilidad y aumentar la contribución de las empresas nacionales, tanto en el mercado local como en el extranjero. Lo que ha llevado a la implementación de varias medidas proteccionistas, que tienen el fin de hacer menos competitivas las empresas extranjeras que estén interesadas en comerciar con el país. Es este el caso de los decretos 074 de 2013 y 456 de 2014 que modifican el arancel de aduanas en textiles y confecciones y se establecen aranceles mixtos, vale anotar que es esta la primera vez que se utilizan este tipo de gravámenes en el país. Lo anterior con los propósitos ya descritos, pero además para controlar

Según las cifras de PIB sectorial, Departamento Administrativo Nacional de Estadística (DANE).

Según cifras de la Encuesta anual manufacturera, DANE.

El volumen de comercio internacional corresponde a la suma de las importaciones y las exportaciones del sector textil. Cálculos propios, TRADEMAP. 
el contrabando por subfacturación de importaciones ${ }^{4}$ que, en los años recientes, ha venido en un aumento preocupante pues ha pasado de un mínimo del $10 \%$ en el año 2012 a casi un 20 \% para el 2015, es decir, la proporción de importaciones subfacturadas de este sector se duplicó en menos de tres años.

Estas políticas implementadas, han sido ampliamente discutidas en entornos económicos, políticos y en prensa nacional por no cumplir con los parámetros instaurados por la Organización Mundial del Comercio $(\mathrm{OMC})^{5}$, pero además porque se cree que podrían tener efectos inversos a los esperados, pues incluso desde la literatura se argumenta que endurecer las barreras a las importaciones termina generando una motivación para contrabandear, ya que los comerciantes tendrán más incentivos para evadir el pago de aranceles cuando estos tienen una gran magnitud (Ferrantino, Liu y Wang, 2012; McDonald, 1985; Fisman y Wei, 2004; Farzanegan, 2009; Buehm y Eichler, 2009).

Es por esto que, en vista de las frecuentes reformas a las tarifas arancelarias y de la controversia al respecto, esta investigación pretende evaluar el efecto de estas políticas sobre la subfacturación de importaciones y sobre el mercado laboral del sector, mediante el uso estimaciones econométricas para de datos panel. Entre los principales resultados, se encuentra que las políticas mencionadas tuvieron un efecto positivo y significativo sobre el contrabando para todo el sector, y para las partidas arancelarias 61, 62, y 636 ${ }^{6}$ corroborando así la hipótesis tradicional de la literatura. Además, los resultados indican que la medida de 2013 tuvo un efecto mayor en la subfacturación que la medida de 2014, en todos los casos. Esto se debe a que los aranceles propuestos en esta política fueron mucho mayores, ya que no consideraba el precio de las mercancías, como sí lo hacia el decreto de 2014. Adicionalmente, desde el mercado laboral, los resultados muestran que estas políticas tuvieron un efecto negativo en las horas trabajadas para todo el sector, y para los trabajadores formales e informales ${ }^{7}$. Sin embargo, el efecto para los formales es mucho menor. Este resultado puede estar impulsado por la existencia de una correlación casi perfecta entre la definición de trabajadores formales utilizada en este artículo y el

4 La subfacturación se entiende como la disminución de precios o cantidades de mercancías que se importan al país, para reducir el pago de tarifas arancelarias.

5 Véase por ejemplo: https://www.elespectador.com/noticias/economia/pleito-los-textiles-panamenosarticulo-647336; https://www.dinero.com/economia/articulo/colombia-baja-aranceles-para-textiles-ycalzado-de-panama/238567

6 Cada partida arancelaria se desagrega en 6, 8 o 10 dígitos, dependiendo de la particularidad que tenga cada producto que se incluye en esta muestra, y para cada producto el tratamiento arancelario puede ser diferenciado.

7 En este documento un trabajador formal se define como una persona ocupada, asalariada que cotiza a salud, y pensión, los informales serán el resto de asalariados. 
hecho de contar con un contrato escrito, pues de acuerdo con datos extraídos de la Gran encuesta integrada de hogares del Departamento Administrativo Nacional de Estadística (DANE), el 96 \% de los empleados formales está sujeto a este tipo de contrato, lo que hace que la dinámica de estos trabajadores sea más rígida y por lo tanto el efecto de las políticas sea de menor magnitud.

Este texto se compone de cinco secciones adicionales a la introducción: en la primera sección se hace una descripción de la política arancelaria en Colombia y de sus recientes modificaciones sobre el sector textil; en la segunda, se realiza una revisión de literatura en torno al contrabando por subfacturación de importaciones; en la tercera, se describen los datos y las metodologías a utilizar; en la cuarta se exponen y analizan los resultados y, posteriormente, se concluye.

\section{POLÍTICA ARANCELARIA EN COLOMBIA}

Desde el año 2006, cuando se adoptó el arancel de aduanas mediante el Decreto 4589 cumpliendo con la modificación del Sistema Armonizado de Designación y Codificación de Mercancías, Colombia ha impuesto aranceles ad valorem, es decir, cobra un porcentaje sobre el precio de las mercancías importadas. Fue solo hasta enero de 2013 con el Decreto 074, que se modificó esta estructura de aranceles. Este decreto afectó específicamente a los productos que pertenecen al sector textil y calzado, específicamente establecía aranceles mixtos compuestos por un gravamen del $10 \%$ y un arancel especifico de US\$5 por kilo bruto para las partidas 61, 62, 63 y 64.06; y este mismo arancel por par de zapatos para la partida $64^{8}$. Es importante aclarar que los gravámenes arancelarios impuestos no eran aplicables a importaciones originarias de países con los que Colombia tuviera vigentes acuerdos comerciales, en cuyo caso, debía aplicarse la tarifa acordada en el respectivo tratado.

Esta política estuvo vigente por un año y se implementó con el ánimo de reactivar el sector y de controlar el contrabando por subfacturación de importaciones, ya que se estaban evidenciando productos del sector textil que llegaban al país con precios extremadamente bajos, con los cuales la industria colombiana no podía competir. Sin embargo, esta medida fue muy controversial porque podría estar violando los aranceles consolidados máximos por la $\mathrm{OMC}^{9}$, por lo cual Panamá, uno de los países más afectados con la política, decidió demandar a Colombia, demanda que falló a

8 Específicamente la partida 61 se refiere a prendas y complementos (accesorios) de vestir, de punto; la partida 62 a prendas y complementos (accesorios) de vestir, excepto los de punto; la partida 63 los demás artículos textiles confeccionados; juegos; prendería y trapos; y la partida 64 sobre el calzado, polainas y artículos análogos y partes de estos artículos.

9 El arancel consolidado máximo de la OMC para el sector textil es del $40 \%$, lo que indica que el arancel compuesto (fijo más ad valorem), no puede sobrepasar este nivel. 
favor del país vecino. En respuesta a esto, Colombia resolvió nuevamente modificar el arancel de aduanas con el Decreto 456 de 2014, pero ahora tendría en cuenta el precio de la mercancía, para lo cual se estableció un gravamen del $10 \%$ y una serie de rangos de precios que definirían el arancel fijo; así, para confecciones cuyo precio fuera menor o igual a US\$10 por kilogramo, se cobraría un arancel de US\$5, y de US\$3 en otro caso; por otro lado, para calzado cuyo precio fuera inferior a US\$7 por par de zapatos, se cobraría un arancel de US\$5, y de US\$1,75 en otro caso.

Esta medida no era la esperada por el país vecino, además, no cumplía, nuevamente, con las normas establecidas por la OMC. Se siguieron presentando tensiones entre los dos países y se pidieron multas millonarias contra Colombia por no cumplir los términos para un comercio internacional justo, pues estas medidas restringían claramente la competencia y, en últimas, perjudicaban a los consumidores, quienes no podrían disfrutar de una oferta variada de productos que fueran asequibles y que, a su vez, cumplieran con altos estándares de calidad. Vale la pena resaltar que más adelante el gobierno nacional tomó la decisión de modificar de nuevo los aranceles para alivianar dichos problemas. Sin embargo, estos últimos cambios no son objeto ya del estudio de este trabajo.

\section{REVISIÓN DE LITERATURA}

La discusión sobre el contrabando técnico inició con el modelo desarrollado por Bhagwati y Hansen (1973) donde se propone la primera medida de subfacturación que se plantea como la diferencia entre el flujo comercial de pares, es decir, el socio importador con el socio exportador. Además, realizan un análisis sobre el efecto del contrabando sobre el bienestar, y encuentran que, a pesar de lo pensando comúnmente, este solo mejora bajo condiciones muy restrictivas. Más tarde, Bhagwati y Srinivasan (1973) estudian la relación entre contrabando y política comercial, concluyen, desde su enfoque teórico, que las políticas comerciales restrictivas generan mayores incentivos a contrabandear.

Varios autores han pretendido establecer un perfil del contrabando en el comercio internacional, como Berger y Nitsch (200international trade statistics should match so that a countrylu2019s exports to a particular partner are identical to the partner u2019s recorded imports from that supplier. In practice, however, these numbers differ, for various reasons. For instance, a major source of discrepancy is the conceptual difference in valuation. Exporting countries report the value of goods at the initial point of departure (FOB8), que examinan discrepancias en las estadísticas del comercio de pares, para una amplia gama de productos. Argumentan que a pesar de que existen algunas causas del porqué las medidas de comercio internacional no 
coinciden entre pares, como los costos de transporte, el desconocimiento del país de destino o de origen y el registro de las transacciones en años diferentes, hay otra posible explicación enfatizada por Fisman y Wei (2009), que indican que la brecha existente entre exportaciones e importaciones puede reflejar el comportamiento criminal sistemático de los comerciantes. Su resultado más importante indica la existencia de una alta correlación entre el contrabando y el nivel de corrupción de los países.

Por otro lado, Buehn y Farzanegan (2012), encaminados en este mismo objetivo, utilizan el modelo de causas e indicadores múltiples (MIMIC) para analizar los determinantes del contrabando y reportan un resultado consistente con la investigación de Fisman y Wei (2009) que indica que factores como la corrupción, un Estado de derecho más débil, aranceles altos y restricciones al comercio fomentan el contrabando. Además, calculan un índice de contrabando para 54 países, lo que les permite determinar zonas del mundo donde es más recurrente o menos recurrente la mala facturación comercial. Otros trabajos se han enmarcado en analizar el contrabando para un sector o país especifico, como Beja (2008), que analiza la dimensión comercial de China para el periodo 2000-2005. Adapta la metodología propuesta por Bhagwati y Hansen (1973) para calcular medidas de subfacturación y sobrefacturación ${ }^{10}$, utilizando información sobre flujos de comercio registrada por los socios de China, y comparándola con los registros provenientes del propio país. El autor encuentra que una gran parte del comercio sufre de problemas de mala facturación o de información no registrada, por lo cual concluye que China necesita un cambio en la agenda comercial y la implementación de métodos de gestión de los flujos comerciales internacionales, para evitar la desviación de recursos por medio del comercio internacional.

Por su parte, Biswas y Marjit (2007) estudian las prácticas comerciales ilegales del mercado de divisas y de capitales. Para esto, estiman un modelo de dos canales de comercio con distintas tarifas arancelarias donde prevalece un arancel bajo o nulo en el canal preferencial y un arancel alto en el canal no preferencial. Sus resultados más importantes indican que es probable que el canal preferencial motive la salida ilegal de capitales, mientras que el canal no preferencial ocasione las transacciones ilegales de divisas. Otra investigación en la misma línea, es la de Goel (2012) que emplea un modelo de datos panel para examinar los efectos de los cigarrillos genéricos en la demanda general de cigarrillos y el contrabando, y estudia las influencias del contrabando casual y organizado para los Estados Unidos. Los

10 Se define sobrefacturación como la práctica en la que un comerciante declara un valor superior al realmente importado. 
hallazgos sugieren que los cigarrillos genéricos tienden a bajar la elasticidad-precio y hacen que el efecto del contrabando formal sea menos pronunciado.

Para el caso de África, Golub y Mbaye (2009) analizan el comercio interregional entre Gambia y Senegal, donde ocurre que, a pesar de ser regiones vecinas, las estadísticas comerciales oficiales no revelan un comercio significativo entre estas. Los autores documentan la magnitud de la protección comercial en las dos regiones, las diferencias de precios resultantes y, posteriormente, estiman el volumen de contrabando. Se atribuyen las altas tasas de contrabando a las diferentes políticas comerciales establecidas por los dos países ya que Gambia es un país con mayores tendencias al libre comercio, mientras Senegal es un país mucho más proteccionista.

Con respecto a la línea teórica, se puede afirmar que se ha incrementado el interés por tratar de explicar los determinantes del contrabando. Una investigación con este propósito es la de Hohzaki y Masuda (2012), que realizan un análisis del contrabando utilizando un modelo de suma cero de teoría de juegos, donde el jugador, es decir, el contrabandista, no obtiene ganancias parciales, solo puede ganarlo o perderlo todo. Introducen, además, información asimétrica y el concepto de equilibrio bayesiano perfecto. Otro trabajo con el mismo objetivo es el de Torres (2016), que estudia los incentivos para la existencia de contrabando a partir de un modelo de teoría de juegos, donde relaciona la decisión del nivel arancelario establecida por el gobierno y la disposición a contrabandear de los comerciantes. Después, realiza una aplicación empírica con un modelo de datos de panel, donde encuentra una relación positiva entre la corrupción y el contrabando y también entre los aranceles y el contrabando técnico.

Para el caso colombiano, el primer trabajo que estudia el problema del contrabando técnico es el de Meisel (1988), que compara las estadísticas de comercio reportadas por los países miembros de las Naciones Unidas, con las estadísticas reportadas por el DANE. Encuentra evidencia de subfacturación para las partidas que corresponden principalmente a productos alimenticos. Más tarde, Steiner y Fernández (1994) y Gómez y Santamaría (1994) realizan un análisis de la evolución del contrabando en Colombia, sus hallazgos indican que este había venido en aumento y se demuestra la existencia de heterogeneidad entre sectores. Por su parte, González (2008) realiza un análisis histórico del contrabando y de otras actividades ilegales en la Guajira. El autor atribuye estas prácticas a la mala regulación y a un factor cultural que, incluso, hace que estos fenómenos se vean con naturalidad y sean aceptados por la población, lo que en últimas termina haciéndolos más difíciles de regular. 
Finalmente, el trabajo que más se acerca al tema de investigación es el realizado por Ronderos (2013), donde examina la conveniencia del Decreto 074 con respecto al impacto que tuvo en el corto plazo sobre variables agregadas como producción y empleo. Para esto realiza una comparación entre los aranceles propuestos en el decreto mencionado y los consolidados por la OMC, y encuentra que, de las 264 posiciones arancelarias analizadas, en 144 subpartidas (54,6 \%) el arancel que se fijó mediante la política superaba al consolidado.

La principal conclusión del autor es que este decreto perjudica a los consumidores con menores ingresos, ya que se evidencia un aumento en los precios domésticos por mayores tasas de protección efectiva (TPE), es decir, el arancel se transfiere mayoritariamente al consumidor. Esto resulta ser muy beneficioso para los empresarios, pues multiplican sus ganancias sin realizar nuevas inversiones. Estos últimos resultados dan una motivación para la realización de este trabajo, pues se pretende verificar de manera más rigurosa y con un lapso de tiempo mayor, las consecuencias de las medidas implementadas sobre el sector textil colombiano con una mirada integral.

\section{METODOLOGÍA Y DATOS}

Como se expresó anteriormente, este trabajo analiza los efectos de las modificaciones del arancel de aduanas ${ }^{11}$ sobre el contrabando por subfacturación de importaciones y el empleo. A continuación, se especifican las metodologías a utilizar en cada caso.

\subsection{Modelo gravitacional de comercio}

Para encontrar un perfil de contrabando de los socios comerciales de Colombia, para productos del sector textil y calzado, se usa el modelo gravitacional de comercio, planteado en un principio por Anderson (1979). El modelo, además de considerar

11 En Colombia los aranceles suelen ser adoptados vía decreto -al igual que las enmiendas 074 y 456 mencionadas anteriormente $\square$ en este caso los aranceles de aduanas o sistemas armonizados totales de Colombia han sido definidos por las siguientes herramientas jurídicas:

- Decreto 255 de 1992.

- Decreto 2317 de 1995.

- Decreto 4341 de 2004.

- Decreto 4589 de 2006.

- Decreto 4927 de 2011.

- Decreto 2153 de 2016. 
las variables tradicionales, como lo son la distancia, vecindad, colonia y lenguaje, también incluye variables para capturar el efecto de los cambios en la política arancelaria. La ecuación se especifica como sigue:

$$
\mathrm{CT}_{i t}=\beta_{0}+\beta_{1} \mathrm{Ml}_{t}+\beta_{2} \mathrm{M}_{t}+\beta_{3} \mathrm{CT}_{i t-1}+\beta_{4} \ln \left(\mathrm{Im}_{i t}\right)+\beta_{5} \mathrm{TLC}_{i t}+\beta_{6} \mathrm{X}_{i}+\mu_{i}+\mu_{t}+\varepsilon_{i t}
$$

Donde $i$ indica el país de origen de la importación y t indica el año. La variable $\mathrm{CT}_{\text {it }}$ es la medida de contrabando por subfacturación de importaciones. Las variables $\mathrm{Ml}_{\mathrm{t}} \mathrm{y} \mathrm{M} 2_{\mathrm{t}}$ son dummies que se activan en el año de implementación de las políticas, es decir, 2013 y 2014, respectivamente. La variable $\mathrm{CT}_{\mathrm{it}-1}$ es el primer rezago de la subfacturación. Esta variable captura la tendencia del contrabando, pues se espera que países que contrabandeen en un periodo repitan esta práctica en periodos posteriores. La variable $\ln \left(\mathrm{Im}_{\mathrm{it}}\right)$ es el logaritmo de las importaciones registradas por Colombia, que es una medida de cuán visible son las importaciones de un país socio, se espera entonces que países más visibles contrabandeen en menor proporción. La variable $\mathrm{TLC}_{\mathrm{it}}$ indica si el país socio tiene vigente un acuerdo comercial con Colombia, se espera que el efecto de esta variable sea negativo, ya que las políticas implementadas solo afectan a países sin acuerdos comerciales ${ }^{12}$. $\mathrm{El}$ vector $\mathrm{X}_{i}$ contiene las variables control que provienen de la estructura tradicional de los modelos de ecuaciones de gravedad, como el logaritmo de la distancia y un conjunto de dummies que se activan cuando los países son vecinos, han tenido relación colonial, fueron el mismo país en algún momento o hablan el mismo idioma, como factores determinantes del comercio internacional. Por último, $\mathrm{a}_{\text {it }}$ son los errores estándar. La estimación además, incluye efectos fijos de país i i y de tiempo $\mu_{\mathrm{t}^{\prime}}$ para controlar las diferencias entre los socios de Colombia y para tener en cuenta las variaciones en el tiempo de la tasa de cambio.

La ecuación 1 se estima para todo el sector textil, que en este ejercicio se define como la suma de los registros para las partidas 61 hasta la 64 del arancel de aduanas, pero también se estima para cada partida de forma independiente, queriendo así detectar distintas dinámicas entre cada partida. Las variables de control se obtienen del Centre d'études prospectives et d'informations internationales (CEPII), que cuenta con información sobre las distancias de los países, y dummies sobre si el país fue colonia, si hablan el mismo idioma, si son vecinos y si en algún momento fueron el

12 No obstante, es importante mencionar que el arancel para países con acuerdo comercial no necesariamente es $0 \%$, sin embargo, estas políticas solo afectan el arancel aplicado a aquellos países con los que no hay acuerdos que anteriormente modificarán aranceles del sector o tuvieran cronogramas de desgravación en ejecución. 
mismo país. Por su parte, la variable TLC fue construida con base en los registros de gravámenes por acuerdos internacionales de la Dirección de Impuestos y Aduanas Nacionales de Colombia (DIAN), donde se especifica el país, el tipo de acuerdo, el arancel y el periodo de vigencia.

Por otro lado, la variable dependiente $\mathrm{CT}_{\mathrm{it}}$ es una medida de contrabando por subfacturación que se calcula de la siguiente manera:

$$
\mathrm{CT}_{i t}=\frac{\text { VRorigen }_{i t}-\mathrm{VRCol}_{i t}}{\text { VRorigen }_{i t}}
$$

Donde VRCol $_{\text {it }}$ son los valores reportados de las importaciones por Colombia, provenientes del país i en el periodo t, y VRorigen ${ }_{i t}$ es el valor reportado por el país de origen. Si esta variable es positiva se puede concluir que existe subfacturación de importaciones. Por el contrario, si la variable es negativa es porque se presenta un caso de sobrefacturación, el cual no hace parte del análisis de este trabajo, cuando esto ocurre el valor es reemplazado por cero, asumiendo que no se evidencia ningún tipo de contrabando. Para calcular esta medida se hizo uso de los registros anuales de las importaciones por partida arancelaria, tanto para Colombia como para el socio exportador, reportados por Trade Statistics for International Business Development (TRADEMAP) desde el 2001 hasta el 2015. En la tabla 1 se presentan las estadísticas descriptivas para el sector textil y para cada partida, donde se muestra que las partidas 62 y 63 son las que más contribuyen a la subfacturación del sector con un promedio de $23,9 \%$ y $23,7 \%$, respectivamente.

Cabe mencionar que se usan datos anuales para tratar de disminuir el sesgo que pueda ser generado por otros motivos que ocasionen que los registros del país de origen y el país de destino no concuerden entre sí, como lo son: el pago de fletes y seguros, el mal registro de las transacciones o el registro de estas en meses distintos por demoras en el paso por la aduana. Es importante aclarar que las estimaciones se realizan con países que subfacturen en, al menos un año, es decir, países que tengan subfacturación igual a cero en todo el periodo de referencia no son incluidos en la muestra para evitar subestimaciones. Esto genera que el número de países difiera en cada estimación. Como indica la tabla 1, la partida que parece ser más subfacturada es la 63, donde se encontraron 91 países con al menos un periodo de subfacturación, y la partida que menos es subfacturada es la 64 con 55 países. En cualquiera de los casos, la cantidad de países que realizan esta práctica es significativamente alta. 
Tabla 1. Estadísticas descriptivas subfacturación, 2001-2015

\begin{tabular}{|l|c|c|c|c|}
\hline \multicolumn{1}{|c|}{ Variable } & Observaciones & Países & Promedio & Desviación estándar \\
\hline Contrabando sector & 1.305 & 85 & $22,42 \%$ & $35,99 \%$ \\
\hline Contrabando partida 61 & 930 & 60 & $21,36 \%$ & $35,47 \%$ \\
\hline Contrabando partida 62 & 1.020 & 66 & $23,89 \%$ & $37,04 \%$ \\
\hline Contrabando partida 63 & 1.380 & 91 & $23,72 \%$ & $38,27 \%$ \\
\hline Contrabando partida 64 & 840 & 55 & $21,99 \%$ & $36,40 \%$ \\
\hline
\end{tabular}

Fuente: elaboración propia con datos de TRADEMAP.

La gráfica 1 muestra la evolución de la subfacturación de importaciones totales para el periodo 2006 2015, se puede inferir que Colombia pasó por una fuerte disminución de la subfacturación, pues a principios del periodo se registraba contrabando para casi el 70 \% de las importaciones, mientras en 2012 se registró un mínimo de casi el 10 \%. Sin embargo, se puede notar un cambio de tendencia desde este año que ha hecho que se presente nuevamente un aumento en esta práctica. Este fenómeno puede estar influenciado por las modificaciones a las políticas arancelarias que se quieren evaluar en este trabajo, pues según la literatura, un aumento en las restricciones al comercio podría fomentar el contrabando.

Gráfica 1. Evolución de la subfacturación en el sector textil, 2006-2015

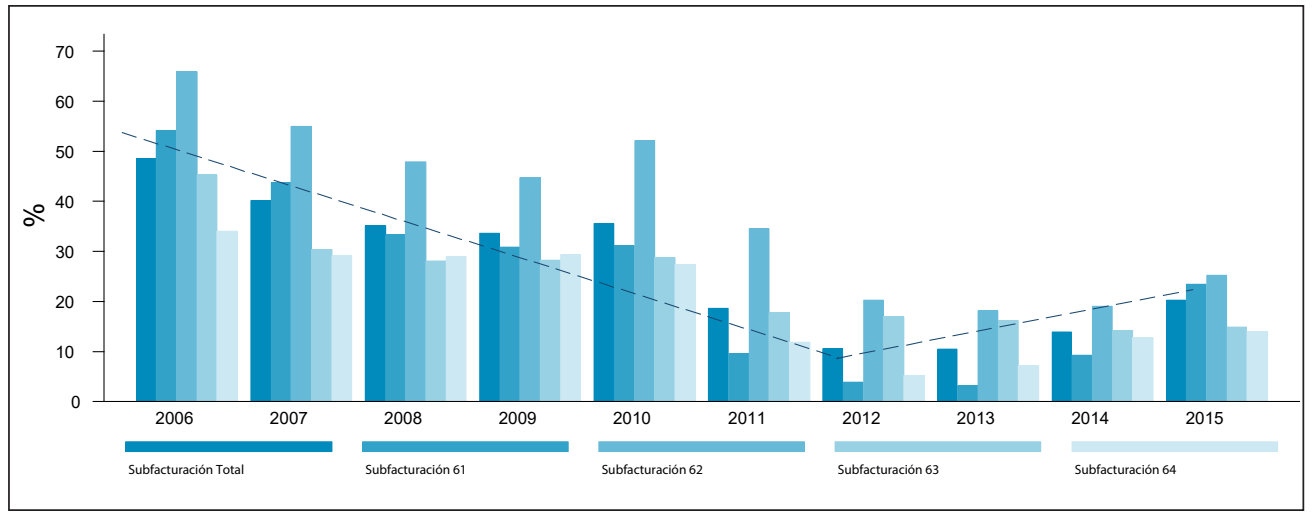

Fuente: elaboración propia con datos de TRADEMAP.

\subsection{Ecuación de Mincer}

Para conocer el efecto de las recientes medidas sobre el empleo, se usa la variable horas trabajadas mensuales como una forma de aproximar la situación laboral 
de los empleados del sector textil. En este ejercicio se implementa una ecuación con una estructura similar a la de Mincer (1974), usada inicialmente para calcular el efecto de la educación sobre los salarios. En este caso, se utilizan variables tradicionales, que reflejan un perfil del trabajador y se incluyen, al igual que en el apartado anterior, variables que capturen el efecto de las políticas. El modelo se especifica a continuación:

$\log \left(\mathrm{Hr}_{i t}\right)=\alpha_{0}+\alpha_{1} \mathrm{Ml}_{t}+\alpha_{2} \mathrm{M}_{t}+\alpha_{3} \log \left(\mathrm{sal}_{i t}\right)+\alpha_{4} \mathrm{X}_{i t}+\alpha_{5} \mathrm{X}_{i t}^{2}+\mu_{t}+\mu_{d}+\mu_{c}+\varepsilon_{i t}$

Donde $t$ indica el periodo; la variable dependiente $\log \left(\mathrm{Hr}_{i t}\right)$ es el logaritmo de las horas trabajadas mensuales del trabajador i; las variables $\mathrm{Ml}_{\mathrm{t}} \mathrm{y} \mathrm{M} \mathrm{M}_{\mathrm{t}}$, como en el primer caso, son dummies que se activan en el año de implementación de las políticas, es decir, 2013 y 2014, respectivamente; la variablelog(sal $\left.{ }_{i t}\right)$ es el logaritmo del salario real mensual. El vector $\mathrm{X}_{\mathrm{it}}$ contiene las variables control que se utilizan en este modelo, las cuales son la edad, los años de educación, los años de experiencia y dummies que capturan el efecto de ser hombre, saber leer y escribir, ser jefe del hogar, y tener un trabajo formal. Por último, el vector $\mathrm{X}_{\text {it }}^{2}$ contiene las variables edad, años de educación y años de experiencia elevadas al cuadrado para detectar posibles relaciones cóncavas o convexas entre las horas trabajadas y estas variables. La estimación, además, incluye efectos fijos de tiempo $\mu_{\mathrm{t}}$, de rama de actividad a dos dígitos de las nomenclaturas del $\mathrm{CIIU}^{13} \mu_{\mathrm{c}^{\prime}}$ y de departamento $\mu_{\mathrm{d}}$, para controlar cambios en la variable de interés que solo se atribuyen a los efectos fijos ya mencionados.

Es importante resaltar de nuevo que en este trabajo se define un empleo formal cuando un trabajador se encuentre cotizando a un fondo de pensiones y esté afiliado a una entidad de seguridad social, pero además que su empleador pague una parte o la totalidad de estas afiliaciones. Esta identificación permite hacer una distinción entre dos tipos de trabajadores que tiene una dinámica totalmente distinta, por lo cual la ecuación 3 se estima para la muestra total y para los trabajadores formales e informales de forma independiente.

La información se obtiene de la Gran encuesta integrada de hogares (GEIH) suministrada por el DANE para el periodo 2007-2016 de forma mensual. El anexo 1 contiene la descripción de las variables que se usan en este ejercicio, al igual que las preguntas que se realizan en la encuesta. Cabe mencionar que la GEIH usa muestras aleatorias distintas para cada periodo, por lo cual, se cuenta con datos de corte trasversal

13 Clasificación Industrial Internacional Uniforme de todas las actividades económicas, revisión 3.1 adaptada para Colombia. DANE. 
repetidos, ya que no se realiza un seguimiento de cada individuo a lo largo del tiempo, pero sí un seguimiento de la dinámica de los trabajadores.

Para tener una muestra de ocupados del sector textil se conservan solo las observaciones que pertenecen a los códigos CIIU 17, 18, y 19, ignorando algunas subpartidas que no corresponden a prendas de vestir o calzado ${ }^{14}$. La tabla 2 presenta la distribución de los datos y el número de observaciones para cada código, se evidencia que la mayor parte de la información pertenece al subsector de fabricación de prendas de vestir, preparado y teñido de pieles con casi el 71 \%, sin embargo, posibles diferencias entre partidas son controladas por el efecto fijo de rama de actividad. La muestra total contiene 87.954 observaciones que se distribuyen de manera uniforme para cada año con en promedio 8.800 observaciones.

Tabla 2. Descripción códigos CIIU a dos dígitos

\begin{tabular}{|c|l|c|c|}
\hline CIIU & \multicolumn{1}{|c|}{ Descripción } & Observaciones & $\%$ \\
\hline 17 & Fabricación de productos textiles. & 7.663 & $8,71 \%$ \\
\hline 18 & $\begin{array}{l}\text { Fabricación de prendas de vestir; preparado y teñido de } \\
\text { pieles. }\end{array}$ & 62.109 & $70,62 \%$ \\
\hline 19 & Fabricación de calzado. & 18.182 & $20,67 \%$ \\
\hline \multicolumn{2}{|c|}{ Total } & \multicolumn{2}{|c|}{87.954} \\
\hline
\end{tabular}

Fuente: elaboración propia con datos de GEIH.

La tabla 3, expone las estadísticas descriptivas de las variables que se usan en la ecuación 3. La primera columna contiene las estadísticas para toda la muestra, mientras que las columnas 2 y 3 presentan las estadísticas para los trabajadores formales y los trabajadores informales, respectivamente. La muestra está compuesta por trabajadores que reciben un salario mensual menor al mínimo legal vigente, pues en promedio ganan aproximadamente 568.000 pesos; dicha población se compone principalmente de personal femenino, con un 70 \% de mujeres, con una edad promedio de 40 años, sin el bachillerato completo, pues su promedio de años de educación es apenas 7, y con cerca de 8 años de experiencia laboral. El 40 \% de los ocupados se declaran jefes de hogar y solo un $23 \%$ es catalogado como trabajador formal según la definición explicada anteriormente. Sin embargo, 47 \% cuenta con un contrato, del cual aproximadamente el 54 \% es escrito. La discriminación de trabajadores formales, indica que existen grandes diferencias en términos de salarios, pues los trabajadores formales ganan aproximadamente $49 \%$ más de lo que ganan los trabajadores informales. En general los formales tiene mejores

14 Específicamente, no se tienen en cuenta en esta muestra los códigos CIIU 1710, 1720, 1741, 1742, 1743, 1910, 1931, 1932 y 1939. 
estadísticas, hay mayor proporción de hombres, más jóvenes y con más años de educación. Sin embargo, es interesante destacar que la experiencia es mucho más alta para los trabajadores informales que cuentan con aproximadamente 12 años de experiencia, mientras los formales tan solo con 6 años. Esta división sugiere, además, que existe una correlación casi perfecta entre tener un contrato escrito y ser un trabajador formal, pues el $96 \%$ de los formales posee un contrato escrito.

Tabla 3. Estadísticas descriptivas GEIH

\begin{tabular}{|l|c|c|c|c|c|c|}
\hline & \multicolumn{2}{|c|}{ Sector } & \multicolumn{2}{c|}{ Formales } & \multicolumn{2}{c|}{ Informales } \\
\hline \multicolumn{1}{|c|}{ Variable } & Media & Des. Est. & Media & Des. Est. & Media & Des. Est. \\
\hline Salario mensual & 568.011 & 709.239 & 760.076 & 746.549 & 509.216 & 686.770 \\
\hline Sexo (hombre) & 0,29 & 0,45 & 0,32 & 0,47 & 0,28 & 0,45 \\
\hline Edad & 40,22 & 13,80 & 35,75 & 10,19 & 41,59 & 14,46 \\
\hline Años de educación & 7,20 & 3,45 & 7,72 & 3,57 & 7,04 & 3,40 \\
\hline Alfabetización & 0,99 & 0,12 & 1,00 & 0,04 & 0,98 & 0,13 \\
\hline $\begin{array}{l}\text { Experiencia en el trabajo } \\
\text { actual (meses) }\end{array}$ & 91,77 & 122,62 & 60,79 & 74,39 & 101,25 & 132,52 \\
\hline Jefe del hogar & 0,40 & 0,49 & 0,37 & 0,48 & 0,41 & 0,49 \\
\hline $\begin{array}{l}\text { Afiliados a un fondo de } \\
\text { pensiones }\end{array}$ & 0,24 & 0,43 & 1,00 & 0,00 & 0,01 & 0,08 \\
\hline Afiliados a salud & 0,25 & 0,43 & 1,00 & 0,00 & 0,02 & 0,15 \\
\hline Contrato & 0,47 & 0,50 & 0,98 & 0,13 & 0,31 & 0,46 \\
\hline Tipo de contrato (escrito) & 0,54 & 0,50 & 0,96 & 0,19 & 0,14 & 0,34 \\
\hline Observaciones & \multicolumn{7}{|c|}{87.954} & 20.614 & & 67.340 \\
\hline
\end{tabular}

Fuente: elaboración propia con datos de GEIH

Con respecto a la distribución de los datos por zonas geográficas, se tiene información para 24 departamentos (de acuerdo con el nivel de cobertura y representatividad estadística de la GEIH en Colombia), pero cabe mencionar que la mayor proporción de observaciones proviene de Antioquia, Santander y Risaralda con $16 \%, 10 \%$ y $8 \%$, respectivamente. No obstante, cualquier diferencia que sea atribuida solo a la zona geográfica es capturada por el efecto fijo de departamento.

\section{RESULTADOS}

\subsection{Subfacturación}

La tabla 4 presenta los resultados de las estimaciones de la ecuación 1 para cinco muestras distintas. La primera columna contiene los resultados para todo el sector (textiles, confecciones y calzado), donde los coeficientes positivos y significativos de 
las variables de política comercial indican que la subfacturación de importaciones se vio incentivada en un $15 \%$ y un $13 \%$ por el cambio en los aranceles establecidos en 2013 y 2014, respectivamente. Por otro lado, la variable logaritmo de las importaciones registradas por Colombia, que se usa como medida de visibilidad del socio, tiene un efecto negativo en el contrabando, lo que indica que países más visibles contrabandean en menor proporción, mientras que el coeficiente del rezago del contrabando es positivo y significativo, corroborando la hipótesis de que los países contrabandean sistemáticamente.

Con respecto a las variables control, los coeficientes negativos y significativos de las variables TLC, distancia, idioma, y mismo país alguna vez, muestran que países con acuerdos comerciales, países más lejanos, países con el mismo idioma y países que fueron la misma nación alguna vez, tienden a contrabandear menos; mientras que los coeficientes positivos y significativos de las variables vecindad y colonia, indican que países vecinos y países con relación colonial contrabandean en mayor magnitud. De la misma forma, en las columnas 2 a 5 se exponen los resultados para las partidas 61 a 64, respetivamente, donde la dinámica para las variables control es la misma descrita anteriormente, pero ya no se encuentran efectos significativos en la variable acuerdo comercial, esto se puede deber a la disminución de la muestra.

Los hallazgos sugieren que para la partida 61 el contrabando se vio motivado en un $26 \%$ y en un $20 \%$ con las políticas de 2013 y 2014 respectivamente, mientras que para la partida 62 el efecto parece a ver sido mayor con un $28 \%$ y un $27 \%$. La partida 63 por su parte, solo se vio afectada por la política de 2014 con un $11 \%$. Por último, con el respecto a la partida 64 , los coeficientes no significativos de las políticas indican que no hubo efectos sobre el contrabando. Es interesante mencionar que, en todos los casos, la política del 2013 tuvo un efecto mayor en el contrabando que la política de 2014. Esto se debe a que el Decreto 074 estableció aranceles mixtos por kilo bruto, mientras que el Decreto 456 tuvo en cuenta el precio de la mercancía, lo que hacía la política un poco menos fuerte, pero, incluso así, con efectos adversos sobre el contrabando.

En el anexo 2, se presentan los resultados para las estimaciones OLS ${ }^{15}$, donde no se incluyen ni efectos fijos de tiempo ni de país. La tabla muestra que el contrabando se vio incentivado por ambas políticas en un $9 \%$ y $6 \%$ para la partida 61 , y solo por la política del 2013 con un $9 \%$ para la partida 62. Lo que indica que no incluir los efectos fijos de país y de tiempo genera una subestimación de los resultados, ya que no se encuentran implicaciones para la muestra total ni para la partida 63 y los coeficientes son sustancialmente menores que los estimados con efectos fijos.

15 Mínimos cuadrados ordinarios, en español. 
Tabla 4. Resultados efectos fijos, subfacturación de importaciones

\begin{tabular}{|c|c|c|c|c|c|}
\hline Variable & Sector & Partida 61 & Partida 62 & Partida 63 & Partida 64 \\
\hline \multirow{2}{*}{ Política arancelaria 2013} & $0,149^{* *}$ & $0,263^{* * *}$ & $0,283^{* * *}$ & 0,096 & 0,020 \\
\hline & $(0,062)$ & $(0,075)$ & $(0,065)$ & $(0,061)$ & $(0,067)$ \\
\hline \multirow{2}{*}{ Política arancelaria 2014} & $0,133^{* *}$ & $0,197^{* * *}$ & $0,269^{* * *}$ & $0,109^{*}$ & 0,068 \\
\hline & $(0,059)$ & $(0,075)$ & $(0,067)$ & $(0,064)$ & $(0,079)$ \\
\hline \multirow{2}{*}{ Logaritmo importaciones } & $-0,053^{* * *}$ & $-0,073^{* * *}$ & $-0,076^{* * *}$ & $-0,080^{* * *}$ & $-0,042^{* * *}$ \\
\hline & $(0,012)$ & $(0,014)$ & $(0,015)$ & $(0,012)$ & $(0,011)$ \\
\hline \multirow{2}{*}{ Rezago del contrabando } & $0,136^{* * *}$ & $0,186^{* * *}$ & 0,038 & 0,054 & $0,111^{*}$ \\
\hline & $(0,046)$ & $(0,056)$ & $(0,053)$ & $(0,038)$ & $(0,068)$ \\
\hline \multirow{2}{*}{ Acuerdo comercial } & $-0,072^{*}$ & $-0,104$ & $-0,062$ & $-0,039$ & $-0,032$ \\
\hline & $(0,041)$ & $(0,077)$ & $(0,051)$ & $(0,051)$ & $(0,060)$ \\
\hline \multirow{2}{*}{ Logaritmo de la distancia } & $-0,292^{* * *}$ & $-0,243^{* * *}$ & $-0,039^{* * *}$ & $-0,212^{* * *}$ & $0,179^{* * *}$ \\
\hline & $(0,015)$ & $(0,009)$ & $(0,010)$ & $(0,015)$ & $(0,014)$ \\
\hline \multirow{2}{*}{ 1: Países vecinos } & $0,139^{*}$ & $0,448^{* * *}$ & $0,361^{* * *}$ & $0,152^{* *}$ & $0,441^{* * *}$ \\
\hline & $(0,082)$ & $(0,088)$ & $(0,075)$ & $(0,060)$ & $(0,092)$ \\
\hline \multirow{2}{*}{ 1: Países con el mismo idioma } & $-0,694^{* * *}$ & $-0,913^{* * *}$ & $-0,748^{* * *}$ & $-0,503^{* * *}$ & $-0,771^{* * *}$ \\
\hline & $(0,077)$ & $(0,086)$ & $(0,095)$ & $(0,084)$ & $(0,089)$ \\
\hline \multirow{2}{*}{ 1: Países con relación colonial } & $0,787^{* * *}$ & $0,885^{* * *}$ & $0,765^{* * *}$ & $0,671^{* * *}$ & $0,280^{* * *}$ \\
\hline & $(0,058)$ & $(0,075)$ & $(0,081)$ & $(0,073)$ & $(0,093)$ \\
\hline \multirow{2}{*}{ 1: El mismo país alguna vez } & $-0,282^{* * *}$ & $-0,442^{* * *}$ & $-0,235^{* * *}$ & $-0,250^{* * *}$ & $0,119^{* * *}$ \\
\hline & $(0,052)$ & $(0,101)$ & $(0,070)$ & $(0,050)$ & $(0,040)$ \\
\hline \multirow{2}{*}{ 1: Mismo lenguaje $9 \%$ población } & $-0,019$ & $0,191^{* * *}$ & $0,190^{* * *}$ & $-0,115^{* * *}$ & $-0,692^{* * *}$ \\
\hline & $(0,030)$ & $(0,054)$ & $(0,033)$ & $(0,038)$ & $(0,056)$ \\
\hline \multirow{2}{*}{ Constante } & $3,335^{* * *}$ & $2,829^{* * *}$ & $1,022^{* * *}$ & $2,647^{* * *}$ & 0,000 \\
\hline & $(0,090)$ & $(0,113)$ & $(0,080)$ & $(0,180)$ & (.) \\
\hline Efectos fijos de tiempo & Sí & Sí & Sí & Sí & Sí \\
\hline Efectos fijos de país & Sí & Sí & Sí & Sí & Sí \\
\hline Observaciones & 1.190 & 840 & 924 & 1.274 & 770 \\
\hline Países & 85 & 60 & 66 & 91 & 55 \\
\hline R-squared within & 0,070 & 0,159 & 0,096 & 0,084 & 0,061 \\
\hline R-squared between & 1,000 & 1,000 & 1,000 & 1,000 & 1,000 \\
\hline R-squared overall & 0,411 & 0,449 & 0,392 & 0,333 & 0,381 \\
\hline
\end{tabular}

Notas: errores estándar en paréntesis. ${ }^{*} p<0,10 ;{ }^{* *} p<0,05 ;{ }^{* * *} p<0,01$

Fuente: elaboración propia 
Con respecto a las variables control, la dinámica ya no es tan clara porque se pierde significancia en los coeficientes dependiendo de la muestra. Por ejemplo, para la muestra total el rezago del contrabando y la relación colonial siguen afectando positivamente la subfacturación, mientras que solo la variable acuerdo comercial la afecta negativamente.

\subsection{Empleo}

La tabla 5 muestra los resultados de las estimaciones de la ecuación 3. La primera columna contiene los resultados para la muestra total, es decir para el sector textil ${ }^{16}$, donde los coeficientes negativos y significativos de las variables de política arancelaria indican que las horas trabajadas mensuales se disminuyeron en un $8 \%$ y $7 \%$, como consecuencia de las medidas implementadas en 2013 y 2014, respectivamente.

Con respecto a las variables control, los coeficientes positivos y significativos de las variables salario, sexo, edad, años de educación y jefe de hogar, muestran que las horas trabajadas se ven incentivadas por ganar un salario mayor, ser hombre, tener más años de edad, tener más años de educación y ser jefe del hogar. Por su parte, los coeficientes negativos y significativos de las variables alfabetización y meses de experiencia sugieren que saber leer y escribir y tener más meses de experiencia laboral reduce las horas trabajadas. Por otro lado, la no significancia de la variable formal indica que no hay diferencias entre las horas trabajadas por los trabajadores formales y los trabajadores informales. Los coeficientes de las variables edad, años de educación y meses de experiencia laboral que se incluyeron, elevadas al cuadrado, para detectar posibles relaciones cóncavas o convexas, son estadísticamente significativos pero su magnitud es prácticamente nula, por lo que se puede decir que no tienen efecto sobre la variable de interés. De la misma manera, las columnas 2 y 3 presentan los resultados para las estimaciones de los trabajadores formales e informales, respectivamente. Se encuentra que las dos políticas tuvieron efectos negativos sobre las horas trabajadas en ambas muestras, sin embargo, este efecto fue de $11 \%$ y $10 \%$ para los trabajadores informales, y de tan solo $0,06 \%$ y $2 \%$ para los trabajadores formales. Esta diferencia entre los efectos para estos dos grupos puede ser atribuida a rigideces en los contratos de los trabajadores formales, que no permiten que se reduzcan en una mayor proporción las horas trabajadas, y que a su vez provoca que los coeficientes para todas las variables sean mucho menores. Con respecto a las variables control, la dinámica es la misma que la descrita anteriormente para la muestra total, pero para los trabajadores formales ya no se encuentra significancia en los coeficientes de las variables años de educación y meses de experiencia.

16 En este ejercicio el sector textil se define como la suma de las partidas 17,18, y 19 del CIIU. 
Tabla 5. Resultados horas mensuales trabajadas

\begin{tabular}{|c|c|c|c|}
\hline Variable & Sector & Formales & Informales \\
\hline \multirow{2}{*}{ Política arancelaria 2013} & $-0,08004^{* * *}$ & $-0,00697^{*}$ & $-0,10962^{* * *}$ \\
\hline & $(0,00580)$ & $(0,00430)$ & $(0,00856)$ \\
\hline \multirow{2}{*}{ Política arancelaria 2014} & $-0,07380^{* * *}$ & $-0,01978^{* * *}$ & $-0,09934^{* * *}$ \\
\hline & $(0,00550)$ & $(0,00384)$ & $(0,00837)$ \\
\hline \multirow{2}{*}{ Logaritmo salario real mensual* } & $0,24754^{* * *}$ & $0,02631^{* * *}$ & $0,26023^{* * *}$ \\
\hline & $(0,00358)$ & $(0,00461)$ & $(0,00395)$ \\
\hline \multirow{2}{*}{ 1: Hombre } & $0,03971^{* * *}$ & $0,00829^{* * *}$ & $0,05327^{* * *}$ \\
\hline & $(0,00321)$ & $(0,00240)$ & $(0,00436)$ \\
\hline \multirow{2}{*}{ Edad } & $0,00569^{* * *}$ & $0,00171^{* *}$ & $0,00482^{* * *}$ \\
\hline & $(0,00069)$ & $(0,00077)$ & $(0,00077)$ \\
\hline \multirow{2}{*}{$\mathrm{Edad}^{\wedge} 2$} & $-0,00010^{* * *}$ & $-0,00002^{* *}$ & $-0,00009^{* * *}$ \\
\hline & $(0,00001)$ & $(0,00001)$ & $(0,00001)$ \\
\hline \multirow{2}{*}{ Años de educación } & $0,01339^{* * *}$ & 0,00058 & $0,01697^{* * *}$ \\
\hline & $(0,00205)$ & $(0,00168)$ & $(0,00255)$ \\
\hline \multirow{2}{*}{ (Años de educación)^2 } & $-0,00072^{* * *}$ & 0,00010 & $-0,00105^{* * *}$ \\
\hline & $(0,00015)$ & $(0,00012)$ & $(0,00018)$ \\
\hline \multirow{2}{*}{ 1: Sabe leer y escribir } & $-0,13773^{* * *}$ & $-0,04766^{*}$ & $-0,15113^{* * *}$ \\
\hline & $(0,01453)$ & $(0,02570)$ & $(0,01553)$ \\
\hline \multirow{2}{*}{ Meses de experiencia } & $-0,00043^{* * *}$ & $-0,00002$ & $-0,00041^{* * *}$ \\
\hline & $(0,00003)$ & $(0,00003)$ & $(0,00004)$ \\
\hline \multirow{2}{*}{$(\text { Meses de experiencia })^{\wedge} 2$} & $0,00000^{* * *}$ & $-0,00000^{* * * *}$ & $0,00000^{* * *}$ \\
\hline & $(0,00000)$ & $(0,00000)$ & $(0,00000)$ \\
\hline \multirow{2}{*}{ 1: Jefe del hogar } & $0,03637^{* * *}$ & $0,00845^{* * *}$ & $0,04409^{* * *}$ \\
\hline & $(0,00275)$ & $(0,00205)$ & $(0,00349)$ \\
\hline \multirow{2}{*}{ 1: Trabajador formal } & $-0,00110$ & & \\
\hline & $(0,00288)$ & & \\
\hline \multirow{2}{*}{ Constante } & $1,96619^{* * *}$ & $4,93967^{* * *}$ & $1,85215^{* * *}$ \\
\hline & $(0,04627)$ & $(0,06920)$ & $(0,05037)$ \\
\hline Efectos fijos de tiempo & $\mathrm{Si}$ & $\mathrm{Si}$ & $\mathrm{Si}$ \\
\hline Efectos fijos de departamento & $\mathrm{Si}$ & $\mathrm{Si}$ & $\mathrm{Si}$ \\
\hline Efectos fijos de código CIIU & $\mathrm{Si}$ & $\mathrm{Si}$ & $\mathrm{Si}$ \\
\hline Observaciones & 87.954 & 20.614 & 67.340 \\
\hline R-squared & 0,34110 & 0,03697 & 0,34202 \\
\hline Adjusted R-squared & 0,341 & 0,034 & 0,341 \\
\hline
\end{tabular}

Notas: errores estándar en paréntesis. ${ }^{*} \mathrm{p}<0,10 * * \mathrm{p}<0,05{ }^{* * *} \mathrm{p}<0,01$. ${ }^{*}$ Deflactado a precios constantes de 2008.

Fuente: elaboración propia 
Es interesante resaltar que para el sector y para los trabajadores informales hubo un mayor efecto en la política de 2013, de la misma forma que en el caso de subfacturación. Sin embargo, en el caso de los formales la política que más tuvo efecto fue la de 2014, esto puede ser producido porque, dada las rigideces en los contratos, los empresarios necesitan más tiempo para ajustar su demanda de trabajo.

\subsection{Comparación con el sector manufacturero}

Con el fin de aproximar de forma más específica la situación del mercado laboral del sector textil, y a modo de prueba de robustez, se realiza una comparación entre el trabajo formal y el trabajo informal del sector con la industria manufacturera ${ }^{17}$. Para este propósito se realiza un ejercicio sencillo de series de tiempo en el que se estima la siguiente ecuación:

$$
\operatorname{Pr}_{t}=\gamma_{0}+\gamma_{1} \mathrm{Ml}_{t}+\gamma_{2} \mathrm{M}_{t}+\gamma_{3} \operatorname{Pr}_{t-1}+\mu_{t}+\varepsilon_{t}
$$

Donde la variable Pr es la participación de los ocupados del sector textil sobre el sector manufacturero; $\mathrm{Pr}_{\mathrm{t}-1}$ es el primer rezago de la participación; i t son efectos fijos de tiempo y $\AA_{t}$ son los errores estándar. La ecuación 4 se estima para tres grupos: todos los ocupados, los ocupados formales y los ocupados informales. Estas muestras son representadas en el gráfico 2, donde se observa que las series de ocupados y ocupados informales tienen una pendiente positiva durante el periodo de implementación de las políticas, mientras la serie de trabajadores formales parece tener un comportamiento estable. Por su parte, cabe resaltar que el sector textil tiene una gran participación sobre el sector manufacturero en términos de empleo, ya que para el último mes del año 2016 contribuyó con casi un 35 \% del total de ocupados. Sin embargo, es lamentable que este sector aporte mayoritariamente empleo informal, pues el $43 \%$ de los empleados informales del sector manufacturero provienen del sector textil, mientras la contribución de trabajo formal de este sector es solo del $20 \%$.

La tabla 6 expone los resultados de las estimaciones de la ecuación 4, la primera columna contiene los resultados para todos los ocupados. El coeficiente positivo y significativo de la política de 2014, muestra que al parecer hubo un aumento de 1,2 \% en los ocupados del sector textil. Sin embargo, si se hace una división por formales e informales, los resultados sugieren que las políticas de 2013 y 2014 se correlacionan con una disminución en el empleo formal de 1,9\% y 1,4\%, y un aumento de los informales en $1,5 \%$ y $3,2 \%$, respectivamente. Lo cual claramente es un hallazgo negativo para el sector que indica un deterioro en las condiciones laborales de los trabajadores, de acuerdo con los parámetros que se establecen internacionalmente desde la perspectiva de trabajo decente planteada por la Organización Internacional del Trabajo (OIT).

${ }_{17}$ El sector manufacturero se define como la suma de las partidas 15 a la 37, según el CIIU. 
Gráfico 2. Participación de los ocupados del sector textil sobre el sector manufacturero

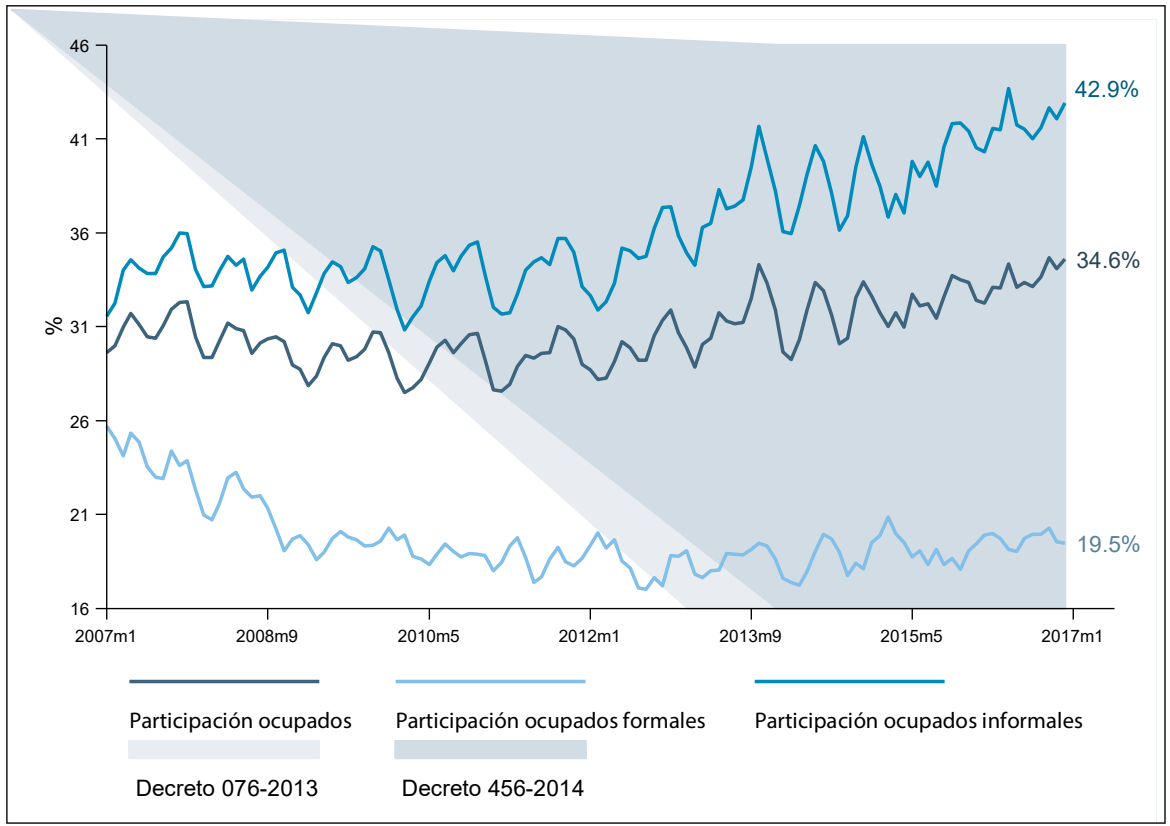

Fuente: elaboración propia con datos de GEIH. Series en promedio móvil trimestral

Tabla 6. Comparación sector textil-manufacturero

\begin{tabular}{|l|c|c|c|}
\hline \multirow{2}{*}{ Variable* } & Sector & Formales & Informales \\
\hline \multirow{2}{*}{ Política arancelaria 2013 } & 0,002 & $-0,019^{* * *}$ & $0,015^{* * *}$ \\
\cline { 2 - 4 } & $(0,00246)$ & $(0,00554)$ & $(0,00413)$ \\
\hline \multirow{2}{*}{ Política arancelaria 2014 } & $0,012^{* * *}$ & $-0,014^{* * *}$ & $0,032^{* * *}$ \\
\cline { 2 - 4 } & $(0,00361)$ & $(0,00477)$ & $(0,00823)$ \\
\hline \multirow{2}{*}{ Rezago participación } & $0,553^{* * *}$ & $0,612^{* * *}$ & $0,572^{* * *}$ \\
\cline { 2 - 4 } & $(0,09973)$ & $(0,07444)$ & $(0,09432)$ \\
\hline \multirow{2}{*}{ Constante } & $0,128^{* * *}$ & $0,090^{* * *}$ & $0,133^{* * *}$ \\
\hline Efectos fijos de tiempo & $(0,03078)$ & $(0,01895)$ & $(0,03176)$ \\
\hline Observaciones & Sí & Sí & Sí \\
\hline R-squared & 119 & 119 & 119 \\
\hline Adjusted R-squared & 0,913 & 0,885 & 0,955 \\
\hline
\end{tabular}

Notas: errores estándar en paréntesis. ${ }^{*} \mathrm{p}<0,10 * * \mathrm{p}<0,05 * * * \mathrm{p}<0,01$. ${ }^{*}$ Series en promedio móvil trimestral Fuente: elaboración propia 
Se evidencia entonces que, a pesar de que disminuyeron en mayor proporción las horas trabajadas por los trabajadores informales, en los años de implementación de las políticas se ha venido reestructurando el mercado laboral, haciendo que este sector genere mayoritariamente empleo informal.

\section{CONCLUSIONES}

El sector textil colombiano ha experimentado frecuentes modificaciones en el arancel de aduanas, argumentando que estas restricciones al comercio mejoran las condiciones del sector y ayudan a combatir el problema del contrabando por subfacturación de importaciones, que en los últimos años ha venido en aumento. Sin embargo, la literatura al respecto, indica que endurecer las barreras a las importaciones termina generando una motivación para contrabandear, ya que los exportadores se verán menos incentivados a pagar aranceles cuando estos tienen una gran magnitud. Es por esto que este trabajo se centra en analizar los efectos de los decretos 074 y 456 de 2013 y 2014, respectivamente, sobre el contrabando y el empleo del sector. Para el primer propósito se hace uso de un modelo gravitacional del comercio en el que la variable de interés es una medida de subfacturación de importaciones, calculada como la diferencia entre los registros del socio exportador y de Colombia. Además, se usan las variables tradicionales del modelo y dummies que capturan el efecto de los decretos antes mencionados. Esta estimación se realiza para todo el sector, definido como la suma de las partidas 61, 62, 63, y 64 del arancel de aduanas; y para cada partida de forma independiente, en el periodo 2001-2015.

Se encuentra que estas políticas tuvieron un efecto positivo y significativo sobre el contrabando para todo el sector, y para las partidas 61, 62, y 63, corroborando así la hipótesis tradicional de la literatura. Además, los resultados indican que la medida de 2013 tuvo un efecto mayor en la subfacturación que la medida de 2014, en todos los casos. Esto se debe a que los aranceles propuestos en esta medida fueron mucho mayores, ya que no consideraba el precio de las mercancías, como sí lo hacia el decreto de 2014.

Por otro lado, para el segundo propósito se utiliza un modelo con una estructura similar a la ecuación de Mincer, para analizar el efecto de las políticas sobre el empleo, en términos de evolución de las horas trabajadas mensuales. El modelo incluye variables para describir el perfil de los trabajadores y dummies para capturar el efecto de las políticas.

Con la intención de identificar diferentes dinámicas entre tipos de trabajadores, la ecuación se estima para la muestra total y para los trabajadores formales e informales de forma independiente, para el periodo 2007-2015; definiendo a un 
trabajador formal como aquel que cotiza a un fondo de pensiones y a una entidad de seguridad social, pero además que su empleador pague una parte o la totalidad de estas afiliaciones.

Los resultados muestran que estas políticas tuvieron un efecto negativo en las horas trabajadas para todo el sector y para los trabajadores formales e informales. Sin embargo, el efecto para los formales es mucho menor. Este resultado puede estar impulsado por la existencia de una correlación casi perfecta entre lo que, en esta investigación se entiende por trabajo formal, y el hecho de contar con un contrato escrito, pues el $96 \%$ de los empleados formales está sujeto a este tipo de contrato. Esto último hace que la dinámica de estos trabajadores sea más rígida y por lo tanto el efecto de las políticas sea de menor magnitud.

Como último ejercicio a modo de chequeo de robustez, se realiza una comparación entre los ocupados del sector textil y los ocupados del sector manufacturero, para así observar la evolución del mercado laboral. Se encuentra que el sector textil tuvo un aumento en la participación con la política de 2014. Sin embargo, cuando se desagrega por empleo formal e informal, se verifica que este aumento está siendo propiciado mayoritariamente por empleo informal, lo cual claramente es un indicador negativo para el sector.

En vista de los anteriores resultados, se puede concluir que las políticas implementadas no cumplieron su objetivo sobre el sector, ya que se presentó un aumento en el contrabando por subfacturación de importaciones, y una desmejora en las condiciones laborales de los empleados, reflejada en un menor número de horas trabajadas y en una especie de desplazamiento de trabajo formal a informal.

Finalmente, es claro que el sector textil colombiano necesita urgentemente que los policy makers concentren sus esfuerzos en estrategias efectivas para reducir la subfacturación y para promover la formalización del empleo. Sin embargo, se hace un llamado a que se procure hacer una revisión exhaustiva de los criterios para establecer este tipo de políticas públicas, donde se consideren los parámetros establecidos internacionalmente y se tenga claridad de los posibles efectos positivos y negativos que puedan generar y de los agentes directamente implicados.

Aunque este trabajo se enfoca en los efectos de las intervenciones en términos de empleo y contrabando técnico, la disponibilidad de información limita el análisis para el estudio de los efectos en producción y ventas de las empresas, y también para analizar efectos en las decisiones de inversión en el sector. Adicionalmente, hay una parte del problema que aún no se ha explorado y es la relativa a los efectos en el contrabando abierto. No obstante, no se descarta ninguna de estas alternativas 
de estudio para futuras líneas de investigación que puedan combinar efectos más diversos, y también aplicar las metodologías utilizadas en este documento para analizar los efectos de políticas similares en otros sectores económicos.

\section{BIBLIOGRAFÍA}

Anderson, James (1979). A Theoretical Foundation for the Gravity Equation. En: The American Economic Review, vol.69, n. 2, marzo, p. 106-116.

Beja, Edsel (2008). Estimating Trade Mis-invoicing from China: 2000-2005. En: China and World Economy, vol.16, n. ${ }^{\circ}$, abril, p. 82-92. Doi: 10.1111/j.1749-124X.2008.00108.x

Berger, Helge y Nitsch, Volker (2008). Gotcha! A Profile of Smuggling in International Trade. En: CESifo Working Paper Series, n. 2475, abril, p. 32

Bhagwati, Jagdish y Hansen, Bent (1973). A Theoretical Analysis of Smuggling. En: The Quarterly Journal of Economics, vol.87, n. ${ }^{\circ}$ 2, mayo, p. 172-187.

Bhagwati, Jagdish y Srinivasan, Thirukodikaval Nilakanta (1973). Smuggling and trade policy. En: Journal of Public Economics, vol.2, n. ${ }^{\circ}$, enero, p. 377-389.

Biswas, Amit y Marjit, Sugata (2007). Preferential trade and mis-invoicing: Some analytical implications. En: International Review of Economics y Finance, vol.16, n. ${ }^{\circ}$ 1, febrero, p. 130-138.

Buehm, Andrea y Eichler, Stefan (2009). Smuggling illegal versus legal goods across the US-Mexico border: a structural equations model approach. En: Southern Economic Journal, n. ${ }^{\circ} 76$, octubre, p. 328-350.

Buehn, Andrea y Farzanegan, Mohammad (2012). Smuggling around the world: evidence from a structural equation model. En: Applied Economics, vol.44, n. ${ }^{\circ} 23$, p. 3047-3064.

Enders, Walter (1995). Applied Econometric Time Series. Nueva York, Estados Unidos de América: Jhon Wiley and Sons, $496 \mathrm{p}$.

El Espectador (2016). Desacuerdo por arancel mixto a textiles y calzado, Economía, Colombia, 1 p.

Farzanegan, Mohammad (2009). Illegal trade in the Iranian economy: evidence from a structural model. En: European Journal of Political Economy, vol. 25, n. ${ }^{\circ}$ 4, diciembre, p. 489-507.

Ferrantino, Michael; Xuepeng, Liu y Zhi, Wang (2012) "Evasion Behaviors of Exporters and Importers: Evidence from the U.S.-China Trade Data Discrepancy." En: Journal of International Economics, vol. 86, n. ${ }^{\circ} 1$, enero, p.141-157.

Fisman, Raymond. y Wei, Shang-Jin (2009). The Smuggling of Art, and the Art of Smuggling: Uncovering the Illicit Trade in Cultural Property and Antiques. En: American Economic Journal: Applied Economics, vol.1, n. ${ }^{\circ}$, julio, p. 82-96.

Fisman, Raymond y Wei, Shang-Jin (2004). Tax rates and tax evasion: evidence from 'missing imports' in China. En: Journal of Political Economy, vol. 112, n. ${ }^{\circ}$ 2, octubre, p. 471 496.

Goel, Rajeev (2012). Effect of generic cigarettes on US cigarette demand and smuggling. En: Economics Letters, vol.115, n. ${ }^{\circ}$, abril, p. 114-117. 
Contrabando técnico y políitica arancelaria: análisis de datos de panel para el sector textil colombiano

Golub, Stephen y Mbaye, Ahmadou (2009). National Trade Policies and Smuggling in Africa: The Case of The Gambia and Senegal. En: World Development, vol.37, n. ${ }^{\circ}$ 3, febrero, p. 595-606.

Gómez, Hernando y Santamaría, Mauricio (1994). La economía subterranea en Colombia. En: Ocampo, José Antonio (ed.). Gran Enciclopedia Temática de Colombia (vol. 8). Bogotá, Colombia: Circulo de Lectores, p. 313-320.

González-Plazas, Santiago (2008). Pasado y presente del contrabando en La Guajira: aproximaciones al fenómeno de ilegalidad en la región. Bogotá, Colombia: Universidad del Rosario, $113 \mathrm{p}$.

Hohzaki, Ryusuke y Masuda, Ryuichi (2012). A smuggling game with asymmetrical information of players. En: The Journal of the Operational Research Society, vol.63, n. ${ }^{\circ}$ 10, octubre, p. $\overline{1434-1446}$. Doi: 10.1057/jors.2011.161

López Mauricio; Torres, Edwin y Giraldo, Sebastían (2016). The evolution of Colombian industry in the context of the energy-mining boom: Symptoms of the dutch disease?. En: Cuadernos de Economía, vol.68, n. 35, enero-junio, p. 475-490.

McDonald, Donogh (1985). Trade data discrepancies and the incentive to smuggle. En IMF Staff Paper, vol. 32, n. ${ }^{\circ}$, p. 668-692.

Meisel, Adolfo (1988). Consideraciones acerca de la presencia de sobre (sub) facturación de las estadísticas de comercio exterior de Colombia. En: Ensayos sobre Política Económica, n. ${ }^{\circ} 14$, diciembre, p. 135-142.

Mincer, Jacob (1974). Schooling, Experience and Earnings. Nueva York, Estados Unidos de América: NBER, 167 p.

Ministerio de Industria y Comercio (2006). Decreto número 4589 de 27 de diciembre de 2006 por el cual se adopta el Arancel de Aduanas y se toman otras disposiciones, 193 p.

Ministerio de Industria y Comercio (2013). Decreto número 0074 de 23 de enero de 2013 por el cual se modifica parcialmente el Arancel de Aduanas, 2 p.

Ministerio de Industria y Comercio (2014). Decreto número 0456 de 28 de febrero de 2014 por el cual se modifica parcialmente el Arancel de Aduanas, 3 p.

Portafolio (2013). Aranceles a ropa y calzado chino irían contra la OMC, Empresas, Colombia, 1 p.

Portafolio (2014). Efecto de sobrearancel a ropa y calzado divide opiniones, Empresas, Colombia, 1 p.

Ronderos, Carlos (2013). Industria de las confecciones, el cuero y el calzado y las actividades del diseño y la moda, en un contexto de protección comercial. Bogotá, Colombia: Universidad Sergio Arboleda, $54 \mathrm{p}$.

Steiner, Roberto y Fernández, Cristina (1994). Evolución y determinantes del contrabando en Colombia. En: Coyuntura Económica, vol. XXIV, n. 3, septiembre, p. 121-141.

Torres, Edwin (2016). Corrupción, incentivos y contrabando técnico en Colombia,1998-2013. Tesis para optar por el titulo de Magíster en Economía. Maestria en Economía, Universidad del Rosario, Colombia, 36 p. 


\section{ANEXOS}

\section{Anexo 1. Descripción de variables GEIH}

\begin{tabular}{|c|c|c|c|}
\hline Módulo & $\begin{array}{c}\text { Variables } \\
\text { GEIH }\end{array}$ & Descripción & Tipo \\
\hline \multirow{7}{*}{$\begin{array}{l}\text { Características } \\
\text { generales }\end{array}$} & P6020 & Sexo & Categórica \\
\hline & P6040 & Años cumplidos & Discreta \\
\hline & P6050 & Parentesco con el jefe del hogar & Categórica \\
\hline & P6110 & ¿Quién paga mensualmente su afiliación a salud? & Categórica \\
\hline & P6160 & ¿Sabe leer y escribir? & Categórica \\
\hline & P6210s1 & Años de educación & Discreta \\
\hline & Área & Área & Discreta \\
\hline \multirow{9}{*}{ Ocupados } & P6450 & ¿Tiene un contrato verbal o escrito? & Categórica \\
\hline & P6426 & ¿Cuánto tiempo lleva trabajando en su empleo actual? & Discreta \\
\hline & P6500 & Antes de descuentos, ¿Cuánto gano el mes pasado? & Continua \\
\hline & P6800 & ¿Cuántas horas a la semana trabaja normalmente? & Discreta \\
\hline & P6940 & $\begin{array}{l}\text { ¿Quién paga mensualmente su afiliación al fondo de } \\
\text { pensiones? }\end{array}$ & Categórica \\
\hline & Inglabo & Ingresos laborales mensuales & Continua \\
\hline & Rama2d & Rama de actividad según el CIIU a dos dígitos & Discreta \\
\hline & Rama4d & Rama de actividad según el CIIU a cuatro dígitos & Discreta \\
\hline & Dpto & Departamento & Discreta \\
\hline
\end{tabular}

Fuente: Microdatos GEIH, DANE. 
Anexo 2. Resultados OLS, subfacturación de importaciones

\begin{tabular}{|c|c|c|c|c|c|}
\hline Variable & Sector & Partida 61 & Partida 62 & Partida 63 & Partida 64 \\
\hline \multirow{2}{*}{ Política arancelaria 2013} & 0,045 & $0,086^{*}$ & $0,087^{*}$ & 0,022 & $-0,049$ \\
\hline & $(0,040)$ & $(0,047)$ & $(0,047)$ & $(0,040)$ & $(0,039)$ \\
\hline \multirow{2}{*}{ Política arancelaria 2014} & 0,021 & $0,055^{*}$ & 0,043 & 0,042 & 0,032 \\
\hline & $(0,030)$ & $(0,032)$ & $(0,036)$ & $(0,031)$ & $(0,038)$ \\
\hline \multirow{2}{*}{ Logaritmo importaciones } & $-0,003$ & $-0,016^{* * *}$ & $-0,000$ & $-0,017^{* * *}$ & 0,008 \\
\hline & $(0,003)$ & $(0,004)$ & $(0,004)$ & $(0,003)$ & $(0,005)$ \\
\hline \multirow{2}{*}{ Rezago del contrabando } & $0,324^{* * *}$ & $0,415^{* * *}$ & $0,293^{* * *}$ & $0,155^{* * *}$ & $0,380^{* * *}$ \\
\hline & $(0,034)$ & $(0,042)$ & $(0,040)$ & $(0,031)$ & $(0,046)$ \\
\hline \multirow{2}{*}{ Acuerdo comercial } & $-0,066^{* *}$ & $-0,045$ & $-0,056$ & $-0,122^{* * *}$ & $-0,081^{*}$ \\
\hline & $(0,031)$ & $(0,038)$ & $(0,035)$ & $(0,036)$ & $(0,042)$ \\
\hline \multirow{2}{*}{ Logaritmo de la distancia } & $-0,042^{* *}$ & $-0,019$ & $-0,037^{*}$ & $-0,030$ & $-0,043$ \\
\hline & $(0,020)$ & $(0,026)$ & $(0,022)$ & $(0,022)$ & $(0,027)$ \\
\hline \multirow{2}{*}{ 1: Países vecinos } & 0,048 & 0,042 & $-0,038$ & $-0,094^{* * *}$ & $-0,176^{* * *}$ \\
\hline & $(0,047)$ & $(0,049)$ & $(0,047)$ & $(0,032)$ & $(0,066)$ \\
\hline \multirow{2}{*}{ 1: Países con el mismo idioma } & $-0,075$ & $-0,191^{* *}$ & $-0,204^{* * *}$ & $0,210^{* * *}$ & $-0,133$ \\
\hline & $(0,080)$ & $(0,092)$ & $(0,069)$ & $(0,071)$ & $(0,095)$ \\
\hline \multirow{2}{*}{ 1: Países con relación colonial } & $0,310^{* * *}$ & $0,270^{* * *}$ & $0,274^{* * *}$ & 0,118 & $-0,033$ \\
\hline & $(0,078)$ & $(0,083)$ & $(0,085)$ & $(0,081)$ & $(0,060)$ \\
\hline \multirow{2}{*}{ 1: El mismo país alguna vez } & 0,125 & $0,192^{* *}$ & $0,254^{* * *}$ & $0,134^{*}$ & $0,200^{* *}$ \\
\hline & $(0,077)$ & $(0,081)$ & $(0,081)$ & $(0,070)$ & $(0,086)$ \\
\hline \multirow{2}{*}{ 1: Mismo lenguaje $9 \%$ población } & $-0,092$ & 0,146 & 0,074 & $-0,122^{*}$ & 0,057 \\
\hline & $(0,079)$ & $(0,096)$ & $(0,068)$ & $(0,070)$ & $(0,095)$ \\
\hline \multirow{2}{*}{ Constante } & $0,567^{* * *}$ & 0,363 & $0,531^{* * *}$ & $0,498^{* *}$ & $0,539^{* *}$ \\
\hline & $(0,178)$ & $(0,231)$ & $(0,197)$ & $(0,203)$ & $(0,247)$ \\
\hline Observaciones & 1.190 & 840 & 924 & 1.274 & 770 \\
\hline Países & 85 & 60 & 66 & 91 & 55 \\
\hline R-squared & 0,142 & 0,205 & 0,113 & 0,088 & 0,147 \\
\hline
\end{tabular}

Notas: Errores estándar en paréntesis. ${ }^{*} p<0,10{ }^{* *} p<0,05 * * * p<0,01$

Fuente: elaboración propia. 